\title{
Influence of Oxygen Tension on Nitrate Reduction by a Klebsiella sp. Growing in Chemostat Culture
}

\author{
By G. M. DUNN,* R. A. HERBERT AND C. M. BROWN \\ Department of Biological Sciences, University of Dundee, Dundee DD1 $4 H N$
}

(Received 21 December 1978)

\begin{abstract}
At dissolved oxygen tensions of $15 \mathrm{mmHg}(2 \mathrm{kPa})$ and below, nitrate-limited continuous cultures of Klebsiella $\mathrm{K} 312$ synthesized nitrate reductase (NR) and nitrite reductase (NiR) and excreted ammonia. Under anaerobic conditions over $60 \%$ of the nitrate-nitrogen utilized was excreted as ammonia. In contrast, carbon-limited cultures excreted nitrite at dissolved oxygen tensions of $15 \mathrm{mmHg}$ or below and synthesized NR but not NiR. Ammonia repressed neither NR nor NiR synthesis. These observations indicate that below a critical oxygen tension of $15 \mathrm{mmHg}$ Klebsiella $\mathrm{K} 312$ utilizes oxygen and nitrate as electron acceptors. This oxygen tension correlates well with the critical oxygen tension observed for a change from oxidative to fermentative metabolism in cultures of Klebsiella aerogenes. The product of dissimilatory nitrate reduction is ammonia in nitrate-limited cultures but principally nitrite in carbon-limited (nitrate excess) cultures.
\end{abstract}

\section{INTRODUCTION}

Nitrate respiration by bacteria grown under anaerobic conditions is a well-documented process occurring in a wide range of facultative and obligate anaerobes (Payne, 1973; Thauer et al., 1977). The reduction of nitrate to nitrite is the best documented step in this system and is catalysed in most bacteria studied by a membrane-bound nitrate reductase (NR, nitrate reductase $\mathrm{A}$ ) which is also able to reduce chlorate. Evidence obtained by measuring the molar growth yields (for the utilization of carbon sources) in anaerobic cultures in the presence and absence of nitrate indicates that nitrate reduction to nitrite is coupled to phosphorylation in a large number of organisms (Stouthamer, 1977). Such phosphorylation is usually associated with a membrane-bound NR, cytochrome $b$ and quinones as electron donors for nitrate reduction (Thauer et al., 1977).

The dissimilatory reduction of nitrite also occurs in a number of bacteria although the end product varies from organism to organism. Denitrifying bacteria such as Paracoccus denitrificans, Thiobacillus denitrificans and many Pseudomonas spp. reduce nitrite to gaseous products (Thauer et al., 1977), for example the reaction $\mathrm{NO}_{2}{ }^{-}+2 \mathrm{H}^{+}+\mathrm{e} \rightarrow \mathrm{NO}+\mathrm{H}_{2} \mathrm{O}$ occurs in cultures of Pseudomonas aeruginosa (Pichinoty, 1973). Alternatively, nitrite may be reduced to ammonia according to the overall reaction $\mathrm{NO}_{2}{ }^{-}+8 \mathrm{H}^{+}+6 \mathrm{e} \rightarrow \mathrm{NH}_{4}{ }^{+}+2 \mathrm{H}_{2} \mathrm{O}$. This process, which is a potentially useful electron sink mechanism, also conserves fixed nitrogen and has been reported to occur in cultures of Klebsiella spp. (Hadjipetrou \& Stouthamer, 1965; Dunn et al., 1978), Achromobacter fischeri (Prakasch \& Sadana, 1973), Veillonella alcalescens (Inderlied \& Delwiche, 1973) and Escherichia coli (Cole, 1978). Dissimilatory nitrite reduction is catalysed by a soluble, NADH-dependent nitrite reductase (NiR) in E. coli (Kemp \& Atkinson, 1966) and a Klebsiella sp. (Dunn et al., 1978).

Dissimilatory nitrate reduction to ammonia is similar overall to assimilatory reduction

\footnotetext{
* Present address: Department of Applied Biology, University of Wales Institute of Science and Technology, Cardiff.
} 
when nitrate serves as culture nitrogen source. The soluble assimilatory NR from $K$. aerogenes (Van't Riet et al., 1968), Azotobacter chroococcum (Guerrero et al., 1973) and a Pseudomonas sp. (Brown et al., 1975) are ammonia-repressible but are not influenced by the dissolved oxygen tension in the culture. In contrast, membrane-bound NR from Pseudomonas denitrificans and Pseudomonas spp. (Chang \& Morris, 1962), Klebsiella spp. (Van't Riet et al., 1968; Dunn et al., 1978), A. fischeri (Prakasch \& Sadana, 1973), Bacillus licheniformis (Schulp \& Stouthamer, 1970), Haemophilus parainfluenzae (Sinclair \& White, 1970), E. coli (Showe \& de Moss, 1968) and T. denitrificans (Justin \& Kelly, 1978) are not ammoniarepressible and are induced maximally in the absence of oxygen.

While it is well-established that nitrate dissimilation occurs maximally in anaerobic cultures, there is little detailed information on the influence of oxygen tension on this process and the synthesis of NR and NiR. Justin \& Kelly (1978) reported that while NR and NiR were synthesized by $T$. denitrificans in the presence of low oxygen concentrations, nitrate reduction occurred only under anaerobic conditions.

In a previous paper we reported that a Klebsiella sp., strain $\mathrm{K} 312$, converted nitrate to ammonia anaerobically in nitrate-limited cultures and that this process was associated with NR and NiR synthesis (Dunn et al., 1978). This report extends these observations to include the influence of oxygen tension on growth, NR and NiR synthesis and the products of dissimilatory nitrate reduction.

\section{METHODS}

Klebsiella sp., strain K312, was isolated by chemostat enrichment from River Tay sediments and has been described by Dunn et al. (1978). Population densities were estimated as viable counts by plating on to Oxoid Tryptone Soy Agar plates followed by incubation at $23{ }^{\circ} \mathrm{C}$ for $48 \mathrm{~h}$. Since this organism produced extracellular polymers when nitrogen-limited, it was not possible to obtain reliable data on culture dry weights.

The defined medium of Evans et al. (1970) was used throughout with the concentrations of all nutrients lowered by $50 \%$. The concentrations of the carbon (glycerol) and nitrogen sources (nitrate or ammonia) were varied as required (Table 1).

The chemostat equipment with automatic control of $\mathrm{pH}(7 \cdot 5)$, temperature $\left(15^{\circ} \mathrm{C}\right)$ and dissolved oxygen tension (in a range from zero to air saturation; $1 \mathrm{mmHg} \approx 133 \mathrm{~Pa}$ ) was as described by Brown \& Rose (1969). A dilution rate of $0 \cdot 1 \mathrm{~h}^{-1}$ was used throughout.

For the determination of NR and NiR activities, about $500 \mathrm{ml}$ culture was centrifuged at $20000 \mathrm{~g}$ for $30 \mathrm{~min}$ at $4{ }^{\circ} \mathrm{C}$. For NR activity determinations, the pellet was washed by resuspending in $50 \mathrm{~mm}-\mathrm{Tris} / \mathrm{HCl}$ buffer ( $\mathrm{pH} \mathrm{7.0)}$ and re-centrifuging. The washed bacteria were resuspended in $8 \mathrm{ml}$ Tris buffer and disrupted by two passages at $110 \mathrm{MPa}$ through a French pressure cell. The homogenate was centrifuged at $30000 \mathrm{~g}$ for $30 \mathrm{~min}$. The pellet was discarded and the supernatant was centrifuged at $125000 \mathrm{~g}$ for $1 \mathrm{~h}$ to give a supernatant (soluble fraction) and pellet (resuspended in $5 \mathrm{ml}$ Tris buffer; particulate fraction) which were assayed for NR activity. For NiR activity determinations, the above procedure was adapted by substituting

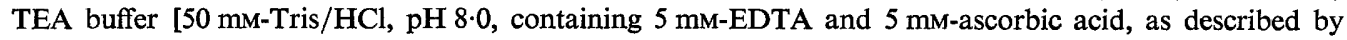
Cole et al. (1974)] for Tris buffer.

NR activity was determined in soluble and particulate fractions using the method of Lowe \& Evans (1964) in which benzyl viologen reduced with dithionite serves as electron donor. NiR activity was determined in soluble fractions, incubated anaerobically in Thunberg cuvettes, by the method of Cole et al. (1974). No NiR activity was detected in particulate fractions.

The protein content of cell extracts was determined by the method of Lowry et al. (1951) using bovine serum albumin as standard. Nitrate, nitrite and ammonia in culture media were determined by methods described by Brown et al. (1972).

\section{RESULTS}

Previously we reported that the maximum production of ammonia from nitrate occurred anaerobically in nitrate-limited cultures (Dunn et al., 1978). In the present study, growth in aerobic, nitrate-limited cultures $(150 \mathrm{mmHg}$ dissolved oxygen tension) was associated with only trace concentrations of nitrate remaining in the spent medium and no detectable excretion of nitrite or ammonia. These cultures contained low activities of NR but no 
Table 1. Influence of oxygen tension on the utilization of nitrate $(a, b)$ or nitrate and ammonia $(c)$ by chemostat cultures of Klebsiella $\mathrm{K} 312\left(D=0 \cdot 1 h^{-1}, 15^{\circ} \mathrm{C}\right)$

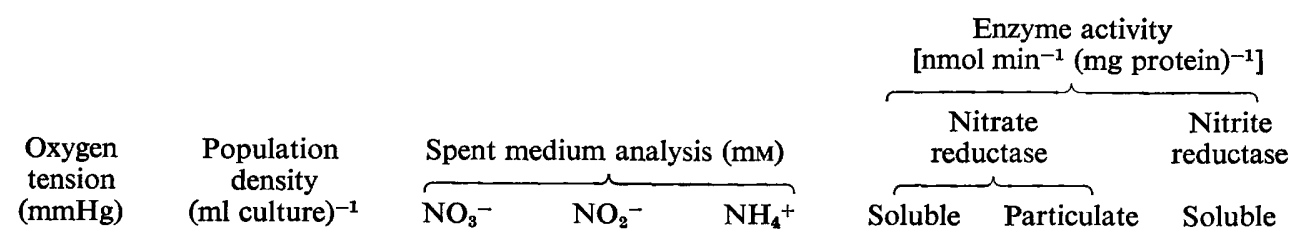

(a) Nitrogen-limited cultures in glycerol/nitrate medium (input: $15 \mathrm{~mm}$-nitrate, $15 \mathrm{~g}$ glycerol $\mathrm{1}^{-1}$ )

$\begin{array}{cccccrrr}150 & 4.9 \times 10^{9} & 0 \cdot 3 & - & - & 12 & 14 & \text { ND } \\ 15 & 2.5 \times 10^{9} & 0 \cdot 3 & - & 2 \cdot 3 & 98 & 195 & 113 \\ 9 & 2.6 \times 10^{9} & 0 \cdot 3 & 0 \cdot 1 & 2 \cdot 1 & 157 & 445 & 58 \\ 0.67 & 1.3 \times 10^{9} & 0 \cdot 1 & 0 \cdot 1 & 4 \cdot 8 & 741 & 642 & 448 \\ \mathrm{~N}_{2} \text { flow } & 1.3 \times 10^{9} & 0 \cdot 1 & - & 9 \cdot 4 & 969 & 2058 & 1314\end{array}$

(b) Carbon-limited cultures in glycerol/nitrate medium (input: $50 \mathrm{~mm}$-nitrate, $5 \mathrm{~g}^{\text {glycerol }} \mathrm{l}^{-1}$ )

$\begin{array}{crrrrrrr}150 & 2.3 \times 10^{9} & 11.5 & 0 \cdot 2 & 0 \cdot 1 & 12 & 12 & \text { ND } \\ 15 & 2.5 \times 10^{9} & 10.4 & 0 \cdot 2 & 0 \cdot 1 & 81 & 370 & \text { ND } \\ 8 & 2.9 \times 10^{9} & 6.6 & 0 \cdot 8 & 0 \cdot 2 & 380 & 704 & \text { ND } \\ 5 & 9.9 \times 10^{8} & 6.5 & 1 \cdot 0 & 0 \cdot 2 & 402 & 1012 & \text { ND } \\ \mathrm{N}_{2} \text { flow } & 8.0 \times 10^{8} & 4.4 & 5.6 & 0.8 & 771 & 1814 & \text { ND }\end{array}$

(c) Carbon-limited cultures in glycerol/nitrate/ammonia medium (input: 50 mM-nitrate, 50 muammonia, 5 g glycerol $1^{-1}$ )

$\begin{array}{crrrrrrr}150 & 3.2 \times 10^{9} & 21.5 & - & 16 \cdot 1 & 31 & 43 & \text { ND } \\ 15 & 3.1 \times 10^{9} & 20.8 & 0.4 & 16.6 & 50 & 390 & \text { ND } \\ 8 & 3.3 \times 10^{9} & 13.5 & 1.9 & 16.9 & 1368 & 3297 & \text { ND } \\ \mathrm{N}_{2} \text { flow } & 8.0 \times 10^{8} & 3.1 & 9.8 & 20.6 & 1277 & 3782 & 1300\end{array}$

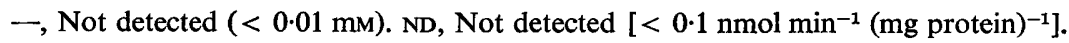

detectable NiR (Table 1 a). Decreasing the culture dissolved oxygen tension to $15 \mathrm{mmHg}$, however, produced a culture with a less efficient utilization of nitrate for growth with about $15 \%$ of the nitrate utilized excreted as ammonia. The activity of particulate NR was some 10 times higher than in aerobically grown cultures and NiR was synthesized in appreciable concentrations. Lowering the culture oxygen tension further, in stages to zero, led to increased amounts of ammonia excreted until under anaerobic conditions this accounted for $62 \%$ of the nitrate utilized. Only traces of nitrate and nitrite were detected at any oxygen tension. The activities of both NR and NiR increased markedly as the oxygen tension was lowered and were highest anaerobically. The culture population density during anaerobic growth was about $25 \%$ of that during aerobic growth, with intermediate counts being obtained at intermediate oxygen tensions.

In contrast to the results from nitrate-limited cultures, ammonia excretion under carbonlimitation (with nitrate present in excess) was slight even under anaerobic conditions (Table $1 b$ ). There was, however, a progressive increase in nitrite excretion and increase in nitrate utilization as the oxygen tension was decreased below $15 \mathrm{mmHg}$. Anaerobically, nitrite excretion accounted for $12 \%$ and ammonia excretion for $2 \%$ of the nitrate utilized. Decreased oxygen tension resulted in a similar increase in NR to that observed in nitratelimited cultures, but no NiR was detected. The population density variations with oxygen tension were similar to those of the nitrate-limited cultures.

The effect of oxygen tension on carbon-limited cultures containing nitrate and ammonia is shown in Table $1(c)$. As in carbon-limited cultures with nitrate alone, both nitrate utilization and nitrite excretion increased as the culture oxygen tension was decreased below $15 \mathrm{mmHg}$. NR activity again increased at low oxygen tensions and NiR was synthesized anaerobically. Population density variations were again of the same order as those noted 
earlier. Analysis of spent media indicated that nitrate and ammonia were assimilated simultaneously at all oxygen tensions and there was some indication that ammonia was excreted anaerobically.

\section{DISCUSSION}

The Klebsiella sp. used in these experiments was able to grow anaerobically with glycerol as carbon source in the absence of nitrate (or nitrite) with ammonia as nitrogen source at a dilution rate of $0 \cdot 1 \mathrm{~h}^{-1}$ (Dunn et al., 1978). This growth was marked, however, by only low population densities $(5.5 \%$ of aerobically grown cells), presumably reflecting the low potential of glycerol as a fermentable carbon source. Anaerobic growth on glycerol in the presence of nitrate, however, produced a higher population density indicating the utilization of nitrate as an electron acceptor in a system coupled to phosphorylation. This dissimilatory nitrate reduction produced only $25 \%$ of the population density attained in aerobic cultures.

The adaptation of the culture to utilize nitrate as electron acceptor was apparent at $15 \mathrm{mmHg}$ with the synthesis of $\mathrm{NR}$ and $\mathrm{NiR}$ (nitrogen-limited culture) and the excretion of the products of nitrate reduction. This effect was more marked at 8 to $9 \mathrm{mmHg}$ and below, with increased enzyme activities, increased product excretion and a decrease in the culture population density. This suggests that oxygen and nitrate are used simultaneously as electron acceptors, evidence which contrasts with the behaviour of cultures of $T$. denitrificans mentioned in the Introduction (Justin \& Kelly, 1978). The 'critical' oxygen tension at which oxygen no longer acts as principal electron acceptor correlates well with the report of Harrison (1972) for the change from oxidative to fermentative metabolism of cultures of $K$. aerogenes growing on glucose. The presence of $\mathrm{NR}$ and $\mathrm{NiR}$ in nitrate-limited cultures (with little residual nitrate) and the absence of NiR in carbon-limited (nitrate excess) cultures suggests that nitrate has some function in the control of NiR. This is not likely to be repression per se because $\mathrm{NiR}$ is synthesized anaerobically in the presence of nitrate and ammonia (Table 1c). Whatever the detailed mechanism, however, it is clear that both NR and $\mathrm{NiR}$ are synthesized anaerobically in the presence of nitrate and ammonia (Table $1 c$ ), that both NR and NiR are required to convert nitrate to ammonia and that ammonia does not repress the synthesis of these dissimilatory enzymes. The induction of NR and NiR at low oxygen tensions is also consistent with this dissimilatory function. The excretion of ammonia from an anaerobic, nitrate-limited culture (Table $1 a$ ) appears paradoxical and such a culture must be considered to be electron acceptor-limited.

Cole (1978) has described the excretion of ammonia by anaerobic cultures of $E$. coli growing on nitrite. In contrast to the Klebsiella sp., cultures of $E$. coli excreted ammonia when carbon- or nitrogen-limited. In $E$. coli, nitrite reduction to ammonia correlated well with a shift in the fermentation pattern of the organism from ethanol to acetate production indicating that nitrite was acting as an oxidizing agent. Cole (1978) further showed that the anaerobic growth yield with nitrite was similar to that with ammonia for $E$. coli, indicating that nitrite reduction was essentially an electron sink mechanism with no oxidative phosphorylation. If this were the case with the Klebsiella sp. it would explain why cultures preferentially reduce nitrate rather than nitrite.

\section{REFERENCES}

Brown, C. M. \& Rose, A. H. (1969). Fatty acid composition of Candida utilis as affected by growth temperature and dissolved oxygen tension. Journal of Bacteriology 99, 371-378.

Brown, C. M., Macdonald-Brown, D.S. \& STANLEY, S. O. (1972). Inorganic nitrogen metabolism in marine bacteria. Nitrogen assimilation in some marine pseudomonads. Journal of the
Marine Biological Association of the United Kingdom 52, 793-804.

Brown, C. M., Macdonald-Brown, D. S. \& STANLEY, S. O. (1975). Inorganic nitrogen metabolism in marine bacteria. Nitrate uptake and reduction in a marine pseudomonad. Marine Biology 31, 7-13.

Chang, J. P. \& Morris, J. G. (1962). Studies on the 
utilization of nitrate by Micrococcus denitrificans. Journal of General Microbiology 29, 301-310.

Cole, J. A. (1978). The rapid accumulation of large quantitities of ammonia during nitrite reduction by Escherichia coli. FEMS Microbiology Letters 4, 327-329.

Cole, J. A., Coleman, K. J., Compton, B. E., Kavenagh, B. M. \& Keevil, C. W. (1974). Nitrite and ammonia assimilation by anaerobic continuous cultures of Escherichia coli. Journal of General Microbiology 85, 11-22.

DunN, G. M., Herbert, R. A. \& Brown, C. M. (1978). Physiology of denitrifying bacteria from tidal mudflats in the River Tay. In Physiology and Behaviour of Marine Organisms, pp. 135-140. Edited by D. S. McLusky \& A. J. Berry. Oxford and New York: Pergamon Press.

Evans, C. G. T., Herbert, D. \& Tempest, D. W. (1970). The continuous culture of microorganisms. 2. Construction of a chemostat. Methods in Microbiology 2, 277-327.

Guerrero, M. G., VeGa, J. M., LeadbetTer, E. \& LOSADA, M. (1973). Preparation and characterisation of a soluble nitrate reductase from Azotobacter chroococcum. Archiv für Mikrobiologie 91, 287-304.

Hadjipetrou, L. P. \& Stouthamer, A. H. (1965). Energy production during nitrate respiration by Aerobacter aerogenes. Journal of General Microbiology 38, 29-34.

Harrison, D. E. F. (1972). Physiological effects of dissolved oxygen tension and redox potential on growing populations of micro-organisms. Journal of Applied Chemistry and Biotechnology 22, $417-440$.

INDERLIED, C. B. \& DelwiChe, E. A. (1973). Nitrate reduction and the growth of Veillonella alcalescens. Journal of Bacteriology 114, 1206-1212.

Justin, P. \& KeLLY, D. P. (1978). Metabolic changes in Thiobacillus denitrificans accompanying the transition from aerobic to anaerobic growth in continuous culture. Journal of General Microbiology 107, 131-137.

KeMP, J. D. \& Atkinson, D. E. (1966). Nitrite reduction of Escherichia coli specific for reduced nicotinamide adenine dinucleotide. Journal of Bacteriology 92, 628-634.

Lowe, R. H. \& Evans, H. J. (1964). Preparation and some properties of a soluble nitrate reductase from Rhizobium japonicum. Biochimica et biophysica acta 85, 377-389.

LOWry, O. H., Rosebrough, N. J., FARR, A. L. \& RANDALL, R. J. (1951). Protein measurement with the Folin phenol reagent. Journal of Biological Chemistry 193, 265-275.

PAYNe, W. J. (1973). Reduction of nitrogenous oxides by microorganisms. Bacteriological Reviews 37, 409-452.

Pichinoty, F. (1973). La reduction bactérienne de composes oxygènes mineraux de l'azote. Bulletin de l'Institut Pasteur 71, 317-395.

Prakasch, O. \& Sadana, J. C. (1973). Metabolism of nitrate in Achromobacter fischeri. Canadian Journal of Microbiology 19, 15-25.

Schulp, J. A. \& Stouthamer, A. H. (1970). The influence of oxygen, glucose and nitrate upon the formation of nitrate reductase and the respiratory system in Bacillus licheniformis. Journal of General Microbiology 64, 195-205.

SHowe, M. K. \& DE Moss, J. A. (1968). Localisation and regulation of nitrate reductase in Escherichia coli. Journal of Bacteriology 95, 1305-1313.

Sinclair, P. R. \& White. D. C. (1970). Effect of nitrate, fumarate and oxygen on the formation of membrane-bound electron transport system of Haemophilus parainfluenzae. Journal of Bacteriology 101, 365-372.

Stouthamer, A. H. (1977). Energetic aspects of the growth of microorganisms. Symposia of the Society for General Microbiology 27, 285-315.

Thauer, R. K., Jungermann, K. \& Decker, K. (1977). Energy conversion in chemotrophic anaerobic bacteria. Bacteriological Reviews 41, 100-180.

Van't Riet, J., Stouthamer, A. H. \& Planta, R. J. (1968). Regulation of nitrate assimilation and nitrate respiration in Aerobacter aerogenes. Journal of Bacteriology 96, 1455-1464. 